\title{
Results of treatment of esophageal variceal hemorrhage with endoscopic injection of n-butyl-2-cyanoacrylate in patients with Child-Pugh class $\mathrm{C}$ cirrhosis
}

Authors

Institutions
Joao Paulo Ribeiro', Sérgio Eiji Matuguma', Spencer Cheng', Paulo Herman ${ }^{1}$, Paulo Sakai ${ }^{1}{ }^{12}$, Luiz Augusto Carneiro D'Albuquerque ${ }^{1,2}$, Fauze Maluf-Filho ${ }^{1,2}$

${ }^{1}$ Department of Gastroenterology, University of São Paulo, São Paulo, Brazil

${ }^{2}$ Laboratory of Investigation of University of São Paulo - LIM37, São Paulo, Brazil submitted 10. June 2014 accepted after revision 16. June 2015

\section{Bibliography}

Dol http://dx.doi.org/

10.1055/s-0034-1392600

Published online: 11.8.2015

Endoscopy International Open 2015; 03: E584-E589

(c) Georg Thieme Verlag KG Stuttgart · New York

E-ISSN 2196-9736

\section{Corresponding author}

Fauze Maluf-Filho, MD, PhD

Av. Brigadeiro Luis Antonio,

4161

CEP 01402-001

São Paulo - SP

Brazil

Fax: +55-11-3884-7599

fauze.maluf@terra.com.br
Background and study aims: The results of endoscopic treatment with elastic band ligation for esophageal variceal bleeding in patients with Child-Pugh class $C$ cirrhosis remain poor. In comparison with treatment with elastic band ligation, we have found lower rates of rebleeding and mortality with n-butyl-2-cyanoacrylate injections. Thus, the aim of the current study was to describe our unit's 10 years of experience with injection of n-butyl-2-cyanoacrylate to control esophageal variceal ruptures in patients with Child-Pugh class C cirrhosis.

Patients and methods: A single-center, retrospective study was conducted. Sixty-three patients with Child-Pugh class $C$ cirrhosis had been admitted to the center with an acute episode of esophageal variceal bleeding. All were treated with injection of n-butyl-2-cyanoacrylate. The patients were assigned to 1 of 2 groups according to their Child-Pugh class C cirrhosis scores: group I (score range, 10 through 13 points) and group II (score, 14 or 15 points). The 3 variables studied were

\section{Introduction}

$\nabla$

Variceal bleeding occurs in $30 \%$ of patients with cirrhosis $[1,2]$. The mortality rate for patients with cirrhosis is $50 \%$ in the first 6 weeks after the first bleeding episode and 30\% after subsequent episodes [2-4]. Secondary prophylaxis is warranted. Otherwise, $60 \%$ of patients who survive the first bleeding episode will experience rebleeding [3].

Patients with Child-Pugh class C cirrhosis, or those with class B cirrhosis with active bleeding at the index endoscopy, are at high risk for treatment failure and have a poor prognosis [5-9]. In a previous randomized controlled trial (RCT), conducted by several investigators among our group (S. E. M., S. C., P. S., and F. M.-F.) and their colleagues [8], 88 patients with esophageal variceal bleeding were treated with sclerotherapy or elastic band li- rates of initial failure to control bleeding, failure to prevent rebleeding (secondary prophylaxis), and mortality. Patients in the 2 groups (group I, $\mathrm{n}=50$; group II, $\mathrm{n}=13$ ) had similar characteristics. Results: Bleeding was successfully controlled in almost $75 \%$ of the patients during the first 5 days after treatment, with no significant differences observed between groups I and II. There were no significant differences between the 2 groups with respect to mortality rate for the first 5 days after treatment. Thirty-four patients (54\%) were free of bleeding at 6 weeks after treatment, with a significant difference noted between the groups: group I, 64\%, versus group II, 15.4\% $(P<0.001)$. The overall mortality rate was $44.4 \%$, with a significant difference noted between the groups: group I, 34\%, versus group II, 84.6\% $(P<0.001)$. Conclusion: Endoscopic injection of n-butyl-2-cyanoacrylate is a valid treatment option to control esophageal variceal bleeding in patients with a Child-Pugh class $\mathrm{C}$ cirrhosis score in the range of 10 through 13 points.
License terms

(ब)(1) $\ominus \circledast$ gation (EBL). Patients with Child-Pugh class C cirrhosis had a 6-week mortality rate of $45.7 \%$, whereas no deaths occurred in the group of patients with Child-Pugh class A cirrhosis $(P<0.001)$. More than a decade ago, several investigators among our group (S. E. M., P. S., and F. M.-F.) and their colleagues [10] compared endoscopic injections of ethanolamine with injections of n-butyl2-cyanoacrylate to treat the first episode of esophageal variceal bleeding in a small RCT of patients with Child-Pugh class $\mathrm{C}$ cirrhosis. The treatment results were favorable in the group who received injections of n-butyl-2-cyanoacrylate [10]. Since then, the treatment of acute esophageal variceal bleeding in patients with Child-Pugh class C cirrhosis with endoscopic injection of n-butyl-2cyanoacrylate has been adopted by our unit in the Department of Gastroenterology, São Paulo University. García-Pagán and colleagues [6] have 
reported that patients with Child-Pugh class $\mathrm{C}$ cirrhosis with a score between 10 and 13 points or those with Child-Pugh class B cirrhosis with active bleeding at endoscopy benefit from early creation of a transjugular intrahepatic portosystemic shunt (TIPS). This finding indicates that there is a need for differentiated therapy for this group of patients [6].

In the current study, our question was whether the results obtained in the RCT conducted by members of our group and their colleagues [8] would be reproducible outside the artificial environment created by RCTs. Thus, our objective was to investigate the following 3 outcomes in patients with Child-Pugh class C cirrhosis who underwent endoscopic injection of n-butyl-2-cyanoacrylate to treat esophageal variceal hemorrhage: (1) rate of failure to control bleeding (up to 5 days after the index bleeding), (2) rate of failure of secondary prophylaxis (from 6 days until 6 weeks after the index bleeding), and (3) complication and mortality rates.

\section{Patients and methods}

$\nabla$

From September 2004 to January 2010, 76 consecutive patients with Child-Pugh class C cirrhosis, who were admitted to Hospital das Clínicas of University of São Paulo School of Medicine with esophageal variceal bleeding, underwent endoscopic treatment with intravariceal injection of n-butyl-2-cyanoacrylate. Of these patients, 13 were excluded from the current study because of incomplete medical records. All patients received intravenous terlipressin and ciprofloxacin before the index endoscopy. We considered esophageal varices as the bleeding source in 3 situations: (1) an endoscopic finding of active variceal bleeding, (2) the presence of a fibrin plug over the varix and blood/fresh clots in the stomach, and (3) the presence of varices without any other potential source of bleeding associated with blood/fresh clots in the stomach. None of the patients had a history of TIPS or surgical interventions for the treatment of portal hypertension.

The patients were divided into 2 groups according to their ChildPugh class $\mathrm{C}$ cirrhosis scores. Patients assigned to group I had a score of $10,11,12$, or 13 points, and those assigned to group II had a score of 14 or 15 points. In addition to group assignment per Child-Pugh class $\mathrm{C}$ cirrhosis scores, records of study participants were evaluated to delineate the following patient characteristics and history (see also $\bullet$ Table 1): demographics (age and sex); cause of cirrhosis; history of variceal bleeding during the past year; type of hemorrhage: primary (patients seeking treatment because of bleeding) versus secondary (patients who presented with gastrointestinal bleeding during hospitalization for other causes); use of a Sengstaken-Blakemore tube for esophageal balloon tamponade before index endoscopy; endoscopic findings of variceal bleeding (active versus recent); and number of ampules of n-butyl-2-cyanoacrylate ( 1 ampule vs $\geq 2$ ampules) used during treatment.

\begin{tabular}{|c|c|c|c|c|c|}
\hline & & No. (\%) & Group I, \% & Group II, \% & \multirow{4}{*}{$\begin{array}{l}\text { Table } 1 \text { Characteristics and his- } \\
\text { tory of patients }(N=63) \text { selected } \\
\text { for study. }\end{array}$} \\
\hline \multicolumn{5}{|l|}{ Age, $y$} & \\
\hline Range & $22-74$ & \multicolumn{3}{|l|}{$63(100)$} & \\
\hline Mean (SD) & $49.9(13)$ & & & & \\
\hline \multicolumn{6}{|l|}{ Child-Pugh class C cirrhosis score } \\
\hline Group I $(10,11,12$, or 13 points $)$ & & $50(79.4)$ & & & \\
\hline Group II (14 or 15 points) & & $13(20.6)$ & & & \\
\hline \multicolumn{6}{|l|}{ Sex } \\
\hline Female & & $13(20.6)$ & 69.2 & 30.8 & \\
\hline Male & & $50(79.4)$ & 82.0 & 18.0 & \\
\hline \multicolumn{6}{|l|}{ Cause of cirrhosis } \\
\hline Alcohol & & $10(15.9)$ & 100 & 0 & \\
\hline Alcohol and virus & & $7(11.1)$ & 100 & 0 & \\
\hline Cryptogenic & & $9(14.3)$ & 66.67 & 33.33 & \\
\hline Virus & & $28(44.4)$ & 78.57 & 21.43 & \\
\hline Other & & $9(14.3)$ & 55.56 & 44.44 & \\
\hline \multicolumn{6}{|c|}{ History of variceal bleeding during the past year } \\
\hline No & & $15(23.8)$ & 73.3 & 26.7 & \\
\hline Yes & & $48(76.2)$ & 81.3 & 18.7 & \\
\hline \multicolumn{6}{|l|}{ Type of hemorrhage } \\
\hline Primary ${ }^{1}$ & & $50(79.4)$ & 88.0 & 12.0 & \\
\hline Secondary ${ }^{2}$ & & $13(20.6)$ & 46.2 & 53.8 & \\
\hline \multicolumn{6}{|c|}{$\begin{array}{l}\text { Use of Sengstaken-Blakemore tube for esophageal balloon } \\
\text { tamponade before index endoscopy }\end{array}$} \\
\hline No & & $56(88.9)$ & 76.8 & 23.2 & \\
\hline Yes & & $7(11.1)$ & 100 & 0 & \\
\hline \multicolumn{6}{|l|}{ Endoscopic findings of variceal bleeding } \\
\hline Active & & $23(36.5)$ & 82.6 & 17.4 & \\
\hline Recent & & $40(63.5)$ & 77.5 & 22.5 & \\
\hline \multicolumn{6}{|c|}{$\begin{array}{l}\text { Ampules of n-butyl-2-cyanoacrylate used during treatment, } \\
\text { no. }\end{array}$} \\
\hline 1 & & $50(79.4)$ & 80.0 & 20.0 & \\
\hline$\geq 2$ & & $13(20.6)$ & 76.9 & 23.1 & \\
\hline
\end{tabular}

$\mathrm{SD}$, standard deviation.

${ }^{1}$ Hemorrhage type was classified as primary for patients seeking treatment because of bleeding.

${ }^{2}$ Hemorrhage type was classified as secondary for patients who presented with gastrointestinal bleeding during hospitalization for other causes. 


\begin{tabular}{|lllcl|} 
& No.(\%) & $\begin{array}{l}\text { Group I, no. (\%) } \\
\text { (n=50) }\end{array}$ & $\begin{array}{l}\text { Group II, no. (\%) } \\
\text { (n=13) }\end{array}$ & P \\
\hline Failure to control bleeding & $16^{1}(25.3)$ & $11^{1}(22.0)$ & $5(38.5)$ & .20 \\
\hline Failure of secondary prophylaxis & $13(27.0)$ & $7(17.5)^{2}$ & $6(75.0)^{3}$ & $<0.001$ \\
\hline Global mortality & $28(44.4)$ & $17(34.0)$ & $11(84.6)$ & .001 \\
\hline
\end{tabular}

Table 2 Results of endoscopic treatment with n-butyl-2-cyanoacrylate injection in patients with Child-Pugh class C cirrhosis.

${ }^{1}$ One patient in whom bleeding failed to be controlled survived the bleeding episode.

2 Data refer to 7 cases (17.5\%) of failure of secondary prophylaxis from 40 patients who were alive to be submitted to secondary prophylaxis.

${ }^{3}$ Data refer to 6 cases $(75.0 \%$ ) of failure of secondary prophylaxis from 8 patients who were alive to be submitted to secondary prophylaxis.

Endoscopic variceal obliteration consists of intravariceal injection of a mixture of $0.5 \mathrm{~mL}$ of n-butyl-2-cyanoacrylate (Histoacryl; B. Braun Melsungen AG, Melsungen, Germany) with $0.7 \mathrm{~mL}$ of iodinated poppy oil (Lipiodol Ultra-Fluid; Braun Laboratory, Rio de Janeiro, Brazil). In brief, the endoscope and the biopsy channel were sprayed with silicone, and the catheter was purged with $0.5 \mathrm{~mL}$ of Lipiodol Ultra-Fluid. Immediately before the injection, the catheter was rinsed with distilled water to keep it free of blood contained in the endoscope channel. The vessel was punctured close to the rupture point. At this point, the water syringe was replaced by another syringe containing the mixture, which was subsequently injected. To push the mixture into the vessel, $1.5 \mathrm{~mL}$ of distilled water was injected shortly thereafter. This volume was usually enough to empty the catheter of its entire contents. If larger volumes of distilled water are quickly injected, nbutyl-2-cyanoacrylate may be washed away from the varix before solidification. Hence, it is necessary to calculate the dead space of the catheter before the procedure. Next, the endoscope was inserted into the stomach, and no fluid was aspirated for approximately 30 seconds to avoid damaging the equipment. The use of Lipiodol Ultra-Fluid slowed the polymerization reaction and enabled us to check the results of the injection through radiologic imaging. The procedure was not performed under the control of fluoroscopy. After injection, the varix was palpated with the catheter to ensure that it had been obliterated. The number of ampules of n-butyl-2-cyanoacrylate used varied from case to case, but the dilution of the mixture was always of the same proportions. When it was impossible to identify the ruptured varices, injection was performed at the larger varices. The n-butyl2-cyanoacrylate injection was performed by a senior endoscopist or by a trainee under supervision. Pulmonary embolism was not routinely investigated after n-butyl-2-cyanoacrylate injection. When clinical conditions allowed patients were referred for sessions of EBL 7 to 10 days after endoscopic treatment of the acute bleeding episode.

We described the results of the endoscopic treatment according to the following criteria, established by the fifth edition of the Baveno International Consensus Workshop [5]: failure to control bleeding: clinically relevant rebleeding occurring up to 5 days after endoscopic treatment; secondary prophylaxis rebleeding: clinically relevant rebleeding occurring 6 days to 6 weeks after endoscopic treatment; and failure of secondary prophylaxis: death occurring 6 days to 6 weeks after endoscopic treatment. We also evaluated complication and mortality rates. We selected age, Child-Pugh class C cirrhosis scores (groups I and II), sex, cause of cirrhosis, history of variceal bleeding, type of hemorrhage (primary or secondary), use of a Sengstaken-Blakemore tube for esophageal balloon tamponade, endoscopic findings of variceal bleeding, and number of injected n-butyl-2-cyanoacrylate ampules at the index endoscopy as potential prognostic factors for the aforementioned outcomes. The patients were monitored for 8 weeks or until death.

\section{Statistical analyses}

The Fisher exact test was used to compare qualitative variables, and the Kruskal-Wallis test was used for quantitative variables. Models of simple and multiple-variable Cox regressions were used to assess time to death and bleeding in the same periods of observation, according to the initial patient characteristics and treatment. For the simple-variable Cox regression analysis, a significance level of $10 \%(P<0.1)$ was adopted, and for the multiplevariable Cox regression analysis, a significance level of $5 \%(P<$ 0.05 ) was adopted. From these models, it was possible to calculate the hazard ratio and its 95\% confidence interval (CI). Finally, graphs of the survival curves were calculated by using the Kaplan-Meier method. The adopted level of significance was $P<$ 0.05 .

\section{Results}

$\nabla$

Between September 2004 and January 2010, 63 patients with Child-Pugh class $\mathrm{C}$ cirrhosis and bleeding due to rupture of esophageal varices were treated with endoscopic injection of nbutyl-2-cyanoacrylate and included in this study. Patient characteristics and history are presented in $\bullet$ Table 1.

Failure to control bleeding, failure of secondary prophylaxis, and overall mortality rates in groups I and II are shown in $\bullet$ Table 2. The rates of failure to control bleeding did not differ between groups I and II ( $22 \%$ and $38.5 \%$, respectively; $P=0.20$ ). The failure rate of secondary prophylaxis was higher in group II than in group I $(75.0 \%$ vs $17.5 \%$, respectively; $P<0.001)$. Thirty-four patients (54\%) were free of bleeding at 6 weeks after treatment, with a significant difference noted between the groups: group I, $64 \%$, versus group II, $15.4 \%(P<0.001)$. The overall mortality rate was higher in group II than in group I ( $84.6 \%$ vs $34.0 \%$, respectively; $P=0.001$ ) ( Fig. 1).

After Cox regression analysis with multiple variables and a significance level of $10 \%(P<0.1)$ for selected variables from the simple Cox regression analysis, we identified previous bleeding and the number of n-butyl-2-cyanoacrylate ampules injected as prognostic factors ( Table 3 ). Only the 48 patients who had survived at least 5 days after the initial treatment were considered when we evaluated prognostic factors for failure of secondary prophylaxis ( Table 4). The risk of failure of secondary prophylaxis for group II patients was 6.59 times higher than that for patients in group I $(P=0.001)$. All patients in whom secondary prophylaxis failed between 6 and 42 days after endoscopy died, whether or not there were further episodes of bleeding. These results confirm the importance of subdividing patients with Child-Pugh class $C$ cirrhosis into those with scores within the range of 10 through 13 points and those with scores of 14 or 15 points as a prognostic factor for secondary prophylaxis failure.

When we investigated mortality, the following criteria were associated with poor prognosis: a Child-Pugh class $\mathrm{C}$ cirrhosis 


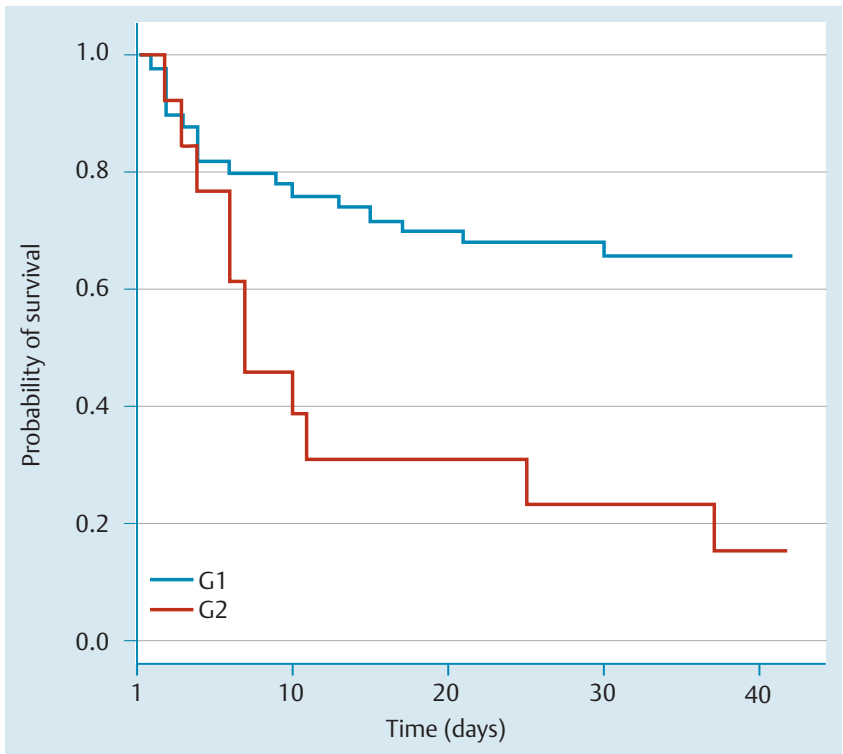

Fig. 1 Overall survival curves ( $N=63)$ : group I (Gl) versus group II (G2).

score of 14 or 15 points, secondary-type hemorrhage, a negative history of previous bleeding, and the need for injection of $\geq 2$ ampules of n-butyl-2-cyanoacrylate. When analyzed together in a multivariate analysis, only the variables Child-Pugh class C cirrhosis score and previous bleeding were relevant. Patients in group II had a 3.32 (95\% CI, 1.53 - 7.19)-fold higher risk of death $(P=0.002)$ in comparison with findings for patients in group I.

\section{Discussion}

The natural history of variceal bleeding in patients with decompensated cirrhosis presents a dismal prognosis. In 2001, we (S. E. M., P. S., and F. M.-F.) and a colleague in our group described better outcomes in patients with Child-Pugh class $\mathrm{C}$ cirrhosis who presented with a first episode of variceal bleeding and were treated with endoscopic obliteration with n-butyl-2- cyanoacrylate, in comparison with findings for patients treated with ethanolamine injections. In this previous study, the rate of reduction of in-hospital mortality was $39 \%$ in absolute values, which resulted in a number needed to treat of 2.5 [10].

Cipolletta and colleagues [11] used n-butyl-2-cyanoacrylate injection to treat patients with cirrhosis admitted for esophageal variceal bleeding, regardless of their Child-Pugh classification score. Once hemostasis had been obtained, EBL was performed for secondary prophylaxis. Their results were encouraging, with an overall mortality rate at 6 weeks of only $8.27 \%$. Unfortunately, it was not possible to discriminate among the results of patients with different Child-Pugh classification scores. More recently, Ljubicić and colleagues [12] compared n-butyl-2-cyanoacrylate and EBL for the treatment of acute esophageal variceal bleeding in patients with cirrhosis, followed by EBL sessions in both groups until variceal eradication. The investigators found no significant differences between the methods. However, it should be noted that results for patients in the different Child-Pugh classes were not compared.

In another 2 studies, n-butyl-2-cyanoacrylate injection was compared with beta blockers or EBL for secondary prophylaxis of variceal esophageal bleeding $[13,14]$. In both studies, patients in the n-butyl-2-cyanoacrylate injection group were treated with repeated endoscopic sessions of glue injection until variceal eradication. No difference was observed between n-butyl-2-cyanoacrylate injection and EBL in treated patients. Instead, local and systemic complications were more common in the group of patients who received n-butyl-2-cyanoacrylate injection. This approach of repeated injections is not appropriate for patients of all Child-Pugh classes, because injection of n-butyl-2-cyanoacrylate causes an intense inflammatory reaction. In the current study, n-butyl-2-cyanoacrylate injections were reserved for the treatment of variceal rupture episodes. For secondary prophylaxis of variceal bleeding, the patients underwent EBL.

In the current study, the clinical characteristics and history of the patients did not differ from those presented in the literature. They were predominantly men in their fifties, viral cirrhosis, primary hemorrhage, and a history of previous bleeding $[8,10]$. In the current study, the rate of failure to control esophageal variceal hemorrhage was $25.3 \%$. It is noteworthy that only 1 patient

\begin{tabular}{|lllll|}
\hline & Hazard ratio & $\mathbf{9 5 \%} \mathbf{C l}$ & \multicolumn{1}{c|}{$\boldsymbol{P}$} \\
\hline Previous bleeding: yes vs no & 0.21 & 0.08 & 0.58 & .002 \\
\hline N-butyl-2-cyanoacrylate: $\geq 2$ ampules vs 1 ampule & 3.74 & 1.34 & 10.41 & .012 \\
\hline
\end{tabular}

$\mathrm{Cl}$, confidence interval.
Table 3 Prognostic factors related to the rate of failure to control bleeding: Cox regression analysis with multiple variables.

\begin{tabular}{|c|c|c|c|c|}
\hline & Hazard ratio & \multicolumn{2}{|c|}{$95 \% \mathrm{Cl}$} & $p$ \\
\hline Child-Pugh class C cirrhosis scores: group II vs group I & 6.59 & 2.2 & 19.77 & .001 \\
\hline Hemorrhage type: secondary vs primary & 2.08 & 0.57 & 7.57 & .266 \\
\hline Previous bleeding: yes vs no & 0.63 & 0.17 & 2.3 & .484 \\
\hline Esophageal balloon tamponade: yes vs no & 0.72 & 0.09 & 5.56 & .755 \\
\hline Endoscopic findings of variceal bleeding: recent vs active bleeding & 0.47 & 0.16 & 1.4 & .174 \\
\hline N-butyl-2-cyanoacrylate: $\geq 2$ ampules vs 1 ampule & 3.14 & 0.96 & 10.24 & .058 \\
\hline \multicolumn{5}{|l|}{ Cirrhosis cause: } \\
\hline Cryptogenic vs alcohol and virus & 1.02 & 0.17 & 6.1 & .984 \\
\hline Virus vs alcohol and virus & 1.24 & 0.17 & 8.85 & .827 \\
\hline Other vs alcohol and virus & 1.01 & 0.2 & 5.02 & .989 \\
\hline
\end{tabular}

Table 4 Prognostic factors for failure of secondary prophylaxis: simple Cox regression analysis.

$\mathrm{Cl}$, confidence interval.

Only the 48 patients who had survived at least 5 days after the initial treatment were considered in evaluation of prognostic factors for failure of secondary prophylaxis. 
(6.2\%) survived rebleeding in the 5 days after the initial treatment. The rate of failure of secondary prophylaxis was $27.0 \%$. It is important to note that according to the fifth edition of the Baveno International Consensus Workshop [5], death due to any cause that occurs within 6 weeks after initial treatment is considered a failure of the endoscopic treatment. Many patients in the current study, especially in group II, died within this period, mostly because of multiple organ failure.

The subclassification of patients with Child-Pugh class $C$ cirrhosis into 2 groups is supported by the literature [6]. García-Pagán and colleagues [6] treated patients with Child-Pugh class B cirrhosis with a score of 9 points and patients with Child-Pugh class $C$ cirrhosis with a score up to 13 points who presented with an acute episode of esophageal variceal hemorrhage. Patients with a Child-Pugh class $C$ cirrhosis score of 14 or 15 points were excluded. All patients received antibiotics and vasoactive drugs and underwent endoscopic evaluation with EBL. They were subsequently randomized to receive placement of TIPS within the first 72 hours or to continue with conservative treatment. The investigators described a 1 -year survival rate of $86 \%$ in the TIPS group, in comparison with $33 \%$ in the conservative treatment group. However, it is important to note that only patients who had been successfully treated with drugs and endoscopic therapy in the first 24 hours were included [6]. Moreover, patients with Child-Pugh class C cirrhosis made up less than $50 \%$ of the sample, and considering that 9 centers included a total of 63 patients, it is apparent that some centers included very few patients, suggesting the possibility of selection bias. In the current study, we obtained a 6week survival rate of $66 \%$ in 50 patients with Child-Pugh class C cirrhosis with a score up to 13 points. We consider this an acceptable outcome, considering the severity of the condition of the patients included in the current study.

The overall mortality rate in the current study was $44.4 \%$, and that described in the original RCT by us (S. E. M., P. S., and F. M.-F.) and colleagues in our group [10] was 33\%. This difference in mortality rate might be due to different levels of expertise with the treatment technique, as well as to the artificial environment created by RCTs and the number of patients with Child-Pugh class C cirrhosis scores of 14 or 15 points involved.

In the current study, patients with a history of previous bleeding presented with better bleeding control and a higher survival rate, in comparison with findings for patients who were admitted with their first episode of variceal rupture. The probable explanation for this is that these patients were already receiving treatment for liver disease with prophylactic drugs and endoscopic treatment for variceal eradication. Another risk factor in the current study for failure to control bleeding was the use of more than 1 ampule of n-butyl-2-cyanoacrylate in an attempt to stop the bleeding. The explanation for this finding probably lies in the fact that these patients presented with torrential variceal bleeding, which often demands more than 1 injection to arrest the hemorrhage.

In comparison with EBL, the endoscopic injection of n-butyl-2cyanoacrylate is technically demanding. This is probably one of the reasons that this technique is underused. Another reason is that in many countries n-butyl-2-cyanoacrylate is not approved for use in endoscopic treatment, despite numerous published papers in which consistently acceptable results regarding n-butyl2-cyanoacrylate treatment of gastric varices have been reported. The main complications associated with n-butyl-2-cyanoacrylate use are thromboembolic [15-18]. Most cases of pulmonary embolism after n-butyl-2-cyanoacrylate injection in gastric varices are due to technical issues, such as speed of the solution injection, volume of glue injected in a single puncture, and volume of Lipiodol Ultra-Fluid used in the injected mixture. Adequate expertise in the technique of n-butyl-2-cyanoacrylate injection is essential to prevent embolic complications. In addition, isolated gastric varices (IGV 1; Sarin and Kumar's classification [19]) are usually associated with spontaneous gastrorenal or splenorenal shunts, into which gastric varices commonly drain. Esophageal varices drain into a complex network of paraesophageal and periesophageal veins that drain into the azygos vein. The small caliber of these veins, the complexity of the venous network, and the correct endoscopic technique of n-butyl-2-cyanoacrylate injection might explain the lower systemic embolism rate of n-butyl-2-cyanoacrylate injection of esophageal varices, in comparison with the rate associated with n-butyl-2-cyanoacrylate injection of gastric varices.

The current study has some limitations that are inherent to a retrospective series, such as patient exclusion for incomplete record as well as the reduced ability to detect complications related to nbutyl-2-cyanoacrylate injection. In addition, the study was underpowered to identify some predictive factors for the studied clinical outcomes.

In conclusion, endoscopic treatment of variceal hemorrhage with n-butyl-2-cyanoacrylate injection in patients with Child-Pugh class $C$ cirrhosis should be considered as a valid therapeutic option for this group of patients. Patients with Child-Pugh class $\mathrm{C}$ cirrhosis scores of $10,11,12$, or 13 points had lower secondary prophylaxis failure and mortality rates, in comparison with findings for patients with Child-Pugh class C cirrhosis scores of 14 or 15 points. The cause of cirrhosis, sex of the patient, and endoscopic findings of variceal bleeding did not seem to affect the results of this treatment.

\section{Competing interests: None}

\section{References}

1 El Atti EA, Nevens F, Bogaerts $K$ et al. Variceal pressure is a strong predictor of variceal haemorrhage in patients with cirrhosis as well as in patients with non-cirrhotic portal hypertension. Gut 1999; 45: $618-$ 621

2 van Buuren HR, Rasch MC, Batenburg PL et al. Endoscopic sclerotherapy compared with no specific treatment for the primary prevention of bleeding from esophageal varices: a randomized controlled multicentre trial [ISRC TN03215899]. BMC Gastroenterol 2003; 3: 22

3 de Franchis R, Bañares R, Silvain C. Emergency endoscopy strategies for improved outcomes. Scand J Gastroenterol Suppl 1998; 226: 25-36

4 McCormick PA, O'Keefe C. Improving prognosis following a first variceal haemorrhage over four decades. Gut 2001; 49: 682-685

5 de Franchis R. Baveno V Faculty. Revising consensus in portal hypertension: report of the Baveno $\mathrm{V}$ consensus workshop on methodology of diagnosis and therapy in portal hypertension. J Hepatol 2010; 53: $762-768$

6 García-Pagán JC, Caca K, Bureau C et al. Early use of TIPS in patients with cirrhosis and variceal bleeding. N Engl J Med 2010; 362: $2370-$ 2379

7 Bittencourt PL, Farias AQ Strauss E et al. Variceal bleeding: consensus meeting report from the Brazilian Society of Hepatology. Arq Gastroenterol 2010; 47: 202-216

8 Luz GO, Maluf-Filho F, Matuguma SE et al. Comparison between endoscopic sclerotherapy and band ligation for hemostasis of acute variceal bleeding. World J Gastrointest Endosc 2011; 3: 95-100

9 North Italian Endoscopic Club for the Study and Treatment of Esophageal Varices. Prediction of the first variceal hemorrhage in patients with cirrhosis of the liver and esophageal varices: a prospective multicenter study. N Engl J Med 1988; 319: 983-989

10 Maluf-Filho F, Sakai P, Ishioka $S$ et al. Endoscopic sclerosis versus cyanoacrylate endoscopic injection for the first episode of variceal bleed- 
ing: a prospective, controlled, and randomized study in Child-Pugh class C patients. Endoscopy 2001; 33: $421-427$

11 Cipolletta L, Zambelli A, Bianco MA et al. Acrylate glue injection for acutely bleeding oesophageal varices: a prospective cohort study. Dig Liver Dis 2009; 41: 729-734

12 Ljubicić $N$, Bisćanin A, Nikolić $M$ et al. A randomized-controlled trial of endoscopic treatment of acute esophageal variceal hemorrhage: N-butyl-2-cyanoacrylate injection vs. variceal ligation. Hepatogastroenterology 2011; 58: 438 - 443

13 Santos MM, Tolentino LH, Rodrigues RA et al. Endoscopic treatment of esophageal varices in advanced liver disease patients: band ligation versus cyanoacrylate injection. Eur J Gastroenterol Hepatol 2011; 23: $60-65$

14 Evrard S, Dumonceau JM, Delhaye M et al. Endoscopic Histoacryl obliteration vs. propranolol in the prevention of esophagogastric variceal rebleeding: a randomized trial. Endoscopy 2003; 35: 729-735
15 Kim EK, Sohn JH, Kim TY et al. [Esophageal sinus formation due to cyanoacrylate injection for esophageal variceal ligation-induced ulcer bleeding in a cirrhotic patient]. Korean J Gastroenterol 2011; 57: $180-183$

16 Martins Santos MM, Correia LP, Rodrigues RA et al. Splenic artery embolization and infarction after cyanoacrylate injection for esophageal varices. Gastrointest Endosc 2007; 65: 1088 - 1090

17 Chen YY, Shen TC, Soon MS et al. Life-threatening pericarditis after Nbutyl-2-cyanoacrylate injection for esophageal variceal bleeding: case report. Gastrointest Endosc 2005; 61: 487-489

18 Gallet B, Zemour G, Saudemont JP et al. Echocardiographic demonstration of intracardiac glue after endoscopic obturation of gastroesophageal varices. J Am Soc Echocardiogr 1995; 8: 759-761

19 Sarin SK, Kumar A. Gastric varices: profile, classification, and management. Am J Gastroenterol 1989; 84: 1244 - 1249 